\title{
Finding Factors for Resilience Using Empowerment Approach: Refugees and Asylum Seekers Coping with Life Adversities
}

\author{
Myeong-Sook Yoon. Sae-Bom Kim \\ Jeonbuk National University, South Korea
}

\begin{abstract}
The strength and resilience of refugees is a less emphasized area as the discourse in refugee mental health study mainly weighs on pathologizing the effects of refugee experiences. This study is concerned with how the mental health of refugees and asylum seekers are affected within these circumstances and it hopes to point out factors of resilience in their newly established life in South Korea. Also, this study aims to pinpoint these factors in light of the strength-based approach. Within the lenses of strength and resilience, this study explored how refugees and asylum seekers, who experienced violence and loss, coped with trauma and hardship in their newly established lives in South Korea. The author analyzed survey data collected from 100 participants (55 asylum seekers and 45 refugees) through open-ended questions. The study analyzed narratives for both content and form and provided evidence for (a) character traits, (b) relationships, (c) skills, (d) knowledge, (e) talents, and (f) abilities that reflect coping strategies used by participants to overcome their life adversities. The findings underscore the importance of considering the strength-based approach either in discussing resilience or intervention. This approach will allow practitioners to acknowledge that refugees and asylum seekers potentially have a unique set of strengths and abilities that they rely on to overcome their immediate and future problems. It will also guide practitioners as they devise their intervention schemes.
\end{abstract}

Keywords: resilience; refugees and asylum seekers; strength; strength-based approach; 